\title{
Estimating Lorenz Curve for Iran by Using Continuous LI Norm Estimation
}

\author{
Bijan Bidabad ${ }^{\mathrm{I}}$
}

\begin{abstract}
In this paper, the LI norm of continuous functions and corresponding continuous estimation of regression parameters are defined. The continuous LI norm estimation problem of one and two parameters linear models in the continuous case are solved. We proceed to use the functional form and parameters of the probability distribution function of income to exactly determine the LI norm approximation of the corresponding Lorenz curve of the statistical population under consideration. Iran family budget data were used to estimate income distribution for the period of I362-I370.
\end{abstract}

Keywords: Li norm, Lorenz Curve, Continuous estimation, Income distribution

\section{Introduction}

The skewness of income distribution is persistently exhibited for different populations and at different times. It is discussed that Pearsonian family distributions are rival functions to explain income distribution. Lorenz curve is a method to analyze the skew distributions. There is a relation between the area under the Lorenz curve and the corresponding probability distribution function of the statistical population (see, Kendall and Stuart (I977)). That is, when the probability distribution function is known, we may find the corresponding Gini coefficient as the measure of inequality.

Estimation of the Lorenz curve is confronted with some difficulties. For this estimation, we should define an appropriate functional form which can accept different curvatures (see, Bidabad and Bidabad (1989a,b)). There is another problem, that is, to create the necessary data set for estimating the corresponding parameters of the Lorenz curve, a large amount of computation on raw sample income data is inevitable. Obviously, these problems, despite their computational difficulties, make the significance of the estimated parameters poor (see, Bidabad and Bidabad (I989a,b)). To avoid this, we try to estimate the functional form of the Lorenz curve by using continuous information. In this paper, we use the probability density function of population income to estimate the Lorenz function parameters. The continuous $\mathrm{L}_{\mathrm{i}}$ norm smoothing method, which will be developed for estimating the regression parameters is used to solve this problem. However, we concentrate on two rival probability density functions of Pareto and log-normal. Since the former is simply integrable, there is no general problem to derive the corresponding Lorenz function, and the function is uniquely derived. But in the latter case, the log-normal density function (which has better performance for full income range) than Pareto distribution (which better fits to higher income range, (see, Cramer (1973), Singh and Maddala (1976), Salem and Mount (1974)), is not integrable and we can not determine its corresponding Lorenz function. In this regard, we should solve the problem by defining a general Lorenz curve functional form and applying the $\mathrm{L}_{\mathrm{I}}$ norm smoothing to estimate the corresponding parameters.

In this paper, continuous LI norm estimation is developed by using a similar method proposed in Bidabad ( $1987 \mathrm{a}, 88 \mathrm{a}, 89 \mathrm{a}, \mathrm{b})$ for the discrete case. Then the method is applied to the estimation of the Lorenz curve functional forms which have been proposed by Gupta (I984) and Bidabad and Bidabad (I989,92). In the end, we use our formulation to estimate Gini ratio and Kakwani length indices of inequality for the United States for the period of I97I-I990, based on the assumption that income is distributed log-normally.

\section{LI norm of continuous functions}

Generally, $L_{p}$ norm of a function $f(x)$ (see, Rice and White (I964)) is defined by,

||$\left.f(x)||_{p}=\int_{x_{E} I}|f(x)| P d x\right)^{I / P}$

Where, "I" is a closed bounded set. The $L_{1}$ norm of $f(x)$ is simply written as,

$$
\left.|| f(x)\right|_{I}=\int_{x_{\varepsilon} I}|(x)| d x
$$

Suppose that the non-stochastic function $f(x, \boldsymbol{\beta})$ of " $x$ ", is combined with stochastic disturbance term "u" to form $y(x)$ as follows,

$$
y(x)=f(x, \boldsymbol{\beta})+u
$$

${ }^{1}$ (B.A., M.Sc., Ph.D., Post-Doc.) Professor of Economics and Chief Islamic Banking Advisor, Bank Melli Iran, bijan@bidabad.com, Bidabad@yahoo.com, http://www.bidabad.com 
Where, $\boldsymbol{\beta}$ is unknown parameters vector. Rewriting $\mathrm{u}$ as the residual of $y(x)-f(x, \boldsymbol{\beta})$, for $L_{1}$ norm approximation of " $\boldsymbol{\beta}$ " we should find " $\boldsymbol{\beta}$ " vector such that the $L_{1}$ norm of " $u$ " is minimum. That is,

$$
\left.\underset{\boldsymbol{\beta}}{\operatorname{Min}: S=|| \mathrm{u} \mid}\right|_{\mathrm{I}}=|| y(\mathrm{x})-\mathrm{f}(\mathrm{x}, \boldsymbol{\beta})\left|{ }_{\mathrm{I}}=\int_{\mathrm{x}_{\varepsilon} \mathrm{I}}\right| \mathrm{y}(\mathrm{x})-\mathrm{f}(\mathrm{x}, \boldsymbol{\beta}) \mid \mathrm{dx}
$$

\section{Linear one parameter LI norm continuous smoothing}

Redefine $f(x, \boldsymbol{\beta})$ as $\beta x$ and $y(x)$ as the following linear function,

$y(x)=\beta x+u$

Where, " $\boldsymbol{\beta}$ " is a single (non-vector) parameter. Expression (4) reduces to: $\min : S=|| u||_{I}=|| y(x)-\beta x||_{I}=\int_{x_{E} I}|y(x)-f(x, \beta)| d x$ $\beta$

The discrete analog of (6) is solved by Bidabad (1987a,88a,89a,b). In these papers, we proposed applying discrete and regular derivatives to the discrete problem by using a slack variable " $t$ " as a point to distinguish negative and positive residuals. A similar approach is used here to minimize (6). To do so in this case, certain Lipschitz conditions are imposed on the functions involved (see, Usow (I967a)). Rewrite (6) as follows,

Min: $S=\int_{x_{\varepsilon} I}|x||y(x) / x-\beta| d x$ $\beta$

For convenience, define "I" as a closed interval $[0, \mathrm{I}]$. The procedure may be applied to other intervals with no major problem (see, Usow (1967a), Hobby and Rice (1965), Kripke and Rivlin (1965)). To minimize this function, we should first remove the absolute value sign of the expression after the integral sign. Since "x" belongs to closed interval "I", $y(x)$ (which is a linear function of " $x$ ") and also $y(x) / x$ are smooth and continuous. Thus, since $y(x) / x$ is uniformly increasing or decreasing function of " $\mathrm{x}$ ", a value of $\mathrm{t} C \mathrm{I}$ can be found to have the following properties,

$$
\begin{array}{ll}
y(x) / x<\beta & \text { if } x<t \\
y(x) / x=\beta & \text { if } x=t \\
y(x) / x>\beta & \text { if } x>t
\end{array}
$$

Value of the slack variable " $t$ " actually is the border of negative and positive residuals. If the value of " $t$ " were known, from (8) (middle equation), we could calculate the optimal value of " $\beta$ " or inversely. But nor " $t$ " neither " $\beta$ " are known. To solve this problem, according to (8), we can rewrite (7) as two separate definite integrals with different upper and lower bounds.

$$
\min _{\beta} S=-\int 0|x|(y(x) / x-\beta) d x+\int t|x|(y(x) / x-\beta) d x
$$

Decomposition of (7) into (8) has been done by use of the slack variable " $t$ ". Since both " $\beta$ " and " $t$ " are unknown, to solve (9), we partially differentiate it with respect to " $t$ " and " $\beta$ " variables.

$$
\underline{\delta S}=\int 0|\mathrm{x}| \mathrm{dx}-\int \mathrm{t}|\mathrm{x}| \mathrm{d} \mathrm{x}=0
$$

$\delta \beta$

and using Liebniz' rule to differentiate the integrals with respect to their variable bounds " $t$ ", yields,

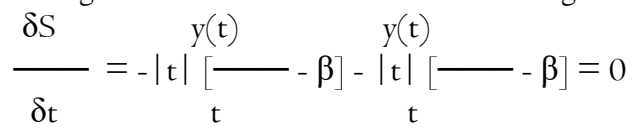

Since " $x$ " belongs to $[0,1]$, equation (I0) can be written as,

$$
\int_{0 x d x-\int t x d x=0}^{t} \int_{x}
$$

or,

$$
1 / 2 t^{2}-1 / 2+1 / 2 t^{2}=0
$$

Which yields,

$$
\mathrm{t}=\sqrt{2} / 2
$$

Substitute for " $t$ " in equation (II), yields,

$$
\beta=\frac{y(\sqrt{ } 2 / 2)}{\sqrt{ } 2 / 2}
$$

Remember that $y(t)$ is function $y(x)$ evaluated at $x=t$. Value of " $\beta$ " given by (I5) is the optimal solution of (6). The above procedure actually is a generalization of Laplace weighted median for the continuous case.

Before applying this procedure to the Lorenz curve, let us develop the procedure for the two parameters linear model. 


\section{Linear two parameters LI norm continuous smoothing}

Now, we try to apply the above technique to the linear two parameters model. Rewrite (4) as,

Min: $S=|| \mathrm{u}||_{\mathrm{I}}=|| y(\mathrm{x})-\alpha-\beta \mathrm{x}||_{\mathrm{I}}=\int_{\mathrm{x}_{\mathrm{E}} \mathrm{I}}\left|\mathrm{y}(\mathrm{x})-\alpha-\beta_{\mathrm{x}}\right| \mathrm{dx}$

$\alpha, \beta$

Where, " $\alpha$ " and " $\beta$ " are two single (non-vector) unknown parameters and $y(x)$ and "x" are as before. According to Rice (I964c), let $\mathrm{f}\left(\alpha^{*}, \beta^{*}, \mathrm{x}\right)$ interpolates $\mathrm{y}(\mathrm{x})$ at the set of canonical points $\{\mathrm{x} ; ; \mathrm{i}=\mathrm{I}, 2\}$, if $\mathrm{y}(\mathrm{x})$ is such that $\mathrm{y}(\mathrm{x}) \mathrm{f}\left(\alpha^{*}, \beta^{*}, \mathrm{x}\right)$ changes sign at these xi's and at no other points in $[0, I]$, then $f\left(\alpha^{*}, \beta^{*}, x\right)$ is the best $L_{1}$ norm approximation to $y(x)$ (see also, Usow (I967a)). With the help of this rule, if we denote these two points to $t_{1}$ and $t_{2}$ we can rewrite $(\mathrm{I} 6)$ for $\mathrm{I}=[0, \mathrm{I}]$ as,

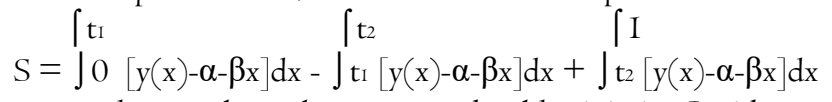

Since $t_{1}$ and $t_{2}$ are also unknowns, we should minimize $S$ with respect to $\alpha, \beta$, ti and $t_{2}$. Taking partial derivative of (I7) using Liebniz' rule with respect to these variables and equating them to zero, we will have,

$$
\begin{aligned}
& \frac{\delta \mathrm{S}}{\delta \alpha}=-\int 0 \mathrm{dx}+\int \mathrm{t}_{1} \mathrm{dx}-\int \mathrm{t}_{2} \mathrm{dx}=0 \\
& \frac{\delta \mathrm{S}}{\delta \beta}=-\int 0 \mathrm{\textrm {t } _ { 2 }} \mathrm{t}_{1} \int \mathrm{t}_{2} \int \mathrm{t}_{\mathrm{t}} \int \mathrm{t}_{1} \mathrm{~d} \mathrm{\textrm {t } _ { 1 }}-\int \mathrm{t}_{2} \mathrm{dx}=0 \\
& \frac{\delta \mathrm{S}}{\delta \mathrm{t}_{1}}=2\left[\mathrm{y}\left(\mathrm{t}_{1}\right)-\alpha-\beta \mathrm{t}_{1}\right]=0 \\
& \frac{\delta \mathrm{S}}{\delta \mathrm{t}_{2}}=-2\left[\mathrm{y}\left(\mathrm{t}_{2}\right)-\alpha-\beta \mathrm{t}_{2}\right]=0
\end{aligned}
$$

Equations (I8) through (2I) may be

$$
\begin{aligned}
& 2 \mathrm{t}_{2}-2 \mathrm{t}_{1}-\mathrm{I}=0 \\
& \mathrm{t}^{2}-\mathrm{t}^{2}-\mathrm{t} / 2=0 \\
& y\left(\mathrm{t}_{1}\right)-\alpha-\beta \mathrm{t}_{1}=0 \\
& \mathrm{y}\left(\mathrm{t}_{2}\right)-\alpha-\beta \mathrm{t}_{2}=0
\end{aligned}
$$

The solutions are,

$$
\begin{aligned}
& \mathrm{t}_{1}=\mathrm{I} / 4 \\
& \mathrm{t}_{2}=3 / 4 \\
& \alpha=y(3 / 4)-(3 / 4) \beta=y(\mathrm{I} / 4)-(\mathrm{I} / 4) \beta \\
& \beta=2[y(3 / 4)-y(\mathrm{I} / 4)]
\end{aligned}
$$

This procedure, similar to that of multiple regression model for discrete case may be expanded to include " $\mathrm{m}$ " unknown parameters which is not discussed here. Some computational methods for solving the different cases of $\mathrm{m}$ parameters model are investigated by Ptak (1958), Rice and White (1964), Rice (1964a,b,c,69,85), Usow (1967a), Lazarski (1975a,b,c,77) (see also, Hobby and Rice (1965), Kripke and Rivlin (1965), Watson (198I)). Now, let us have a look at Lorenz curve and its proposed functional forms.

\section{Lorenz curve}

The Lorenz curve for a random variable with probability density function $\mathrm{f}(\mathrm{v})$ may be defined as the ordered pair ${ }^{2}$,

$$
\left(P(V \mid V \leq v), \frac{E(V \mid V \leq v)}{E(V)}\right) \quad v \varepsilon R
$$

Where "P" and "E" stand for probability and expected value operators. For a continuous density function $\mathrm{f}(\mathrm{v}),(30)$ can be written as,

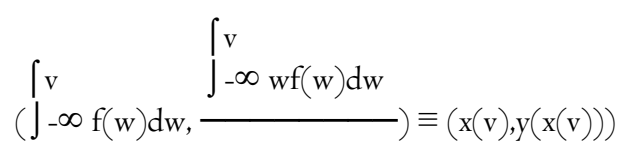

\footnotetext{
${ }^{2}$ Taguchi $(1972 a, b, c, 73,81,83,87,88)$ multiplies the second element of (30) by $P(V \mid V \leq V)$ which is not correct; his definition of (31) is equivalent to ours.
} 


$$
\int \begin{aligned}
& +\infty 1 \\
& -\infty w f(w) d w
\end{aligned}
$$

We denote (3I) by $(x(v), y(x(v)))$ where $x(v)$ and $y(x(v))$ are its elements. Therefore, " $x$ " is a function which maps "v" to $x(v)$ and " $y$ " is a function which maps $x(v)$ to $y(x(v))$. The function $y(x(v))$ is simply the Lorenz curve function. In recent years some functional forms for the Lorenz curve have been introduced. Among different proposed functions, we use the forms of Gupta (1984) and Bidabad and Bidabad (1989,92) which benefits from certain properties (see their articles for more explanations). Gupta (1984) proposed the functional form,

$$
y={ }_{x} A^{x-1} \quad A>I
$$

Bidabad and Bidabad $(1989,92)$ suggest the following functional form:

$$
y=x^{B} A^{x-1} \quad B \geq I, A \geq I
$$

To estimate the above functions by regular estimating method, we should gather discrete data from the statistical population, and manipulate them to construct relevant $\mathrm{x}$ and $\mathrm{y}$ vectors to estimate "A" of (32) or "A" and "B" of (33). If the probability distribution of income is known, instead of gathering discrete observations, we can estimate the Lorenz curve by using the continuous $\mathrm{L}_{1}$ norm smoothing method for continuous functions. In the following section, we proceed to apply this method to estimate the parameters "A" of (32) and "A" and "B" of (33) by using the information of probability density function of income.

\section{Continuous LI norm smoothing of Lorenz curve}

To estimate the Lorenz curve parameters when income probability density function is known, we can not always take straightforward steps. When the probability density function is easily integrable, there is no major problem in advance. We can find the functional relationship between the two elements of (3I) by simple mathematical derivation. But, when integrals of (3I) are not obtainable, another procedure should be adopted.

Suppose that the income of society is distributed with probability density function $f(w)$. This density function may be a skewed function such as Pareto or log-normal, as follows

$$
\begin{aligned}
& f(w)=\theta k \theta w-\theta-I, \quad w r k>0, \theta>0 \\
& f(w)=[I / w \sigma \sqrt{ }(2 \pi)] \exp \left\{-[\ln (w)-\mu]^{2} / 2 \sigma^{2}\right\}, \quad w \varepsilon(0, \infty), \mu \varepsilon(-\infty,+\infty), \sigma>0
\end{aligned}
$$

These two distributions have been known as good candidates for presenting the distribution of personal income.

In the case of Pareto density function of (34), we can simply derive the Lorenz curve function as follows. Let $F(w)$ denote the Pareto distribution function:

$$
\mathrm{F}(\mathrm{w})=\mathrm{I}-(\mathrm{k} / \mathrm{w}) \theta
$$

with mean equal to,

$$
\mathrm{E}(\mathrm{w})=\theta^{\mathrm{k}} /(\theta-\mathrm{I}), \theta>\mathrm{I}
$$

If we find the function $y$ as stated by $(3 \mathrm{I})$ as a function of $\mathrm{x}$, the Lorenz function will be derived. Now, proceed as follows. Rearrange the terms of (3I) as,

$$
\begin{aligned}
& x(v)=\int-\infty f(w) d w \\
& y(x(v))=[I / E(x)]]-\infty \quad w f(w) d w
\end{aligned}
$$

Substitute Pareto distribution function,

$$
\begin{aligned}
& x(v)=F(v)=I-(k / v)^{\theta} \\
& y(x(v))=\left[(\theta-I) / \theta^{k}\right] J k w \theta k^{\theta} w^{-\theta_{-I}} d w
\end{aligned}
$$

or,

$$
y(x(v))=I-(k / v)^{\theta-I}
$$

Now, by solving (40) for " $\mathrm{v}$ " and substituting in (42), the Lorenz curve for Pareto distribution is derived as, $y=I-(I-x)^{\left(\theta_{-}\right) / \theta}$

As it was shown in the case of Pareto distribution, formula of Lorenz curve is easily obtained. But, if we select the log-normal density function (35), the procedure may not be the same. Because the integral of log-normal function has not been derived yet. In the following pages, the $\mathrm{L}_{\mathrm{I}}$ norm smoothing technique will be developed to estimate the parameters of given functional forms (32) and (33) by using the continuous probability density function.

According to (30) and (3I) independent and dependent variables of (32) and (33) may be written as,

$$
\begin{aligned}
& x(v)=\int 0 f(w) d w \\
& y(x(v))=[I / E(x)] \int 0 w f(w) d w
\end{aligned}
$$


Substitute (44) and (45) inside (32) and define random error term $u$ as,

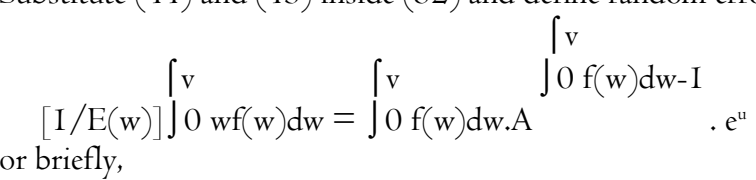

$$
\begin{aligned}
& y(x)={ }_{x A} A^{x-1} e^{u} \\
& \text { Similarly for the model (35), }
\end{aligned}
$$$$
[\mathrm{I} / \mathrm{E}(\mathrm{w})] \int 0 \mathrm{vf}(\mathrm{w}) \mathrm{dw}=\left\{\int 0 \mathrm{f}(\mathrm{w}) \mathrm{dw}\right\} . \mathrm{A} \int^{\int \mathrm{v}} \mathrm{f}(\mathrm{w}) \mathrm{dw}-\mathrm{I} . \mathrm{e}^{u}
$$$$
\text { or briefly, }
$$$$
y(x)={ }_{x}^{B} A^{x-1} e^{u}
$$

Taking natural logarithm of (47) and (49), gives,

$$
\begin{aligned}
& \ln y(x)=\ln x+(x-I) \ln A+u \\
& \ln y(x)=B \cdot \ln x+(x-I) \ln A+u
\end{aligned}
$$

With respect to properties of Lorenz curve and probability density function of $f(w)$ and equations (46) to (49), it is obvious that $\mathrm{x}$ belongs to the interval $[0, \mathrm{I}]$. Thus the Li norm objective function for minimizing $(50)$ or $(5 \mathrm{I})$ is given by,

$$
\min : S=\int 0|u| d x
$$

Now, let us deal with Li norm estimation of "A" of Lorenz curve functional form (32) (redefined by (50)). The corresponding Li norm objective function will be,

$$
\underset{A}{\min : S}=\int 0|\ln y(x)-\ln x-(x-I) \ln A| d x
$$

or,

$$
\min _{A} \mathrm{~S}=\int 0|x-I||[\ln y(x)-\ln x] /(x-I)-\ln A| d x
$$

By a similar technique used by (9), we can rewrite (54) as,

$$
\min : S=\int 0|x-I|\{[\ln y(x)-\ln x] /(x-I)-\ln A\} d x-\int t|x-I|\{[\ln y(x)-\ln x] /(x-I)-\ln A\} d x
$$$$
\text { A }
$$

since, $0 \leq x \leq$ I we have,

$$
\min : S=-\int 0[\ln y(x)-\ln x-(x-I) \ln A] d x+\int t[\ln y(x)-\ln x-(x-I) \ln A] d x
$$

Differentiate (56) partially with respect to " $\mathrm{t}$ " and "A" and equate them to zero;

$$
\delta \mathrm{S} \quad \int \mathrm{t} \quad\{\mathrm{I}
$$

$\delta \mathrm{A}$

$$
\frac{\delta \mathrm{S}}{\delta \mathrm{t}}---2[\ln y(\mathrm{t})-\ln \mathrm{t}-(\mathrm{t}-\mathrm{I}) \ln \mathrm{A}]=0
$$

From equation (57), we have,

$$
\mathrm{t}=\mathrm{I} \pm \sqrt{2} / 2
$$

Since " $t$ " should belong to the interval $[0, I]$, we accept,

$$
\mathrm{t}=\mathrm{I}-\sqrt{2} / 2
$$

Substitute (60) in (58), and solve for "A", gives the $\mathrm{L}_{1}$ norm estimation for "A" equal to,

$$
\left.A=\frac{I-\sqrt{2} / 2}{y(I-\sqrt{2} / 2)}\right]^{\sqrt{2}}
$$

Now, let us apply this procedure to another Lorenz curve functional form of (33) (redefined by (5I)). Rewrite LI norm objective function (52) for the model (5I), 


$$
\underset{A, B}{\min : S=\int 0|\ln y(x)-B \ln x-(x-I) \ln A| d x}
$$

or,

$$
\begin{aligned}
& \int I \\
& \min , \mathrm{B}
\end{aligned}
$$

The objective function (63) - by some changing on variables - is similar to (I6). Thus, by a similar procedure to those of (I7) through (29) we can write "S" as,

$$
\begin{aligned}
& \min : S=\int 0|x-I|\{[\ln y(x)] /(x-I)-(\ln x) /(x-I)-\ln A\} d x \\
& \text { A,B } \\
& -\int t_{1}|x-I|\{[\operatorname{lng}(x)] /(x-I)-(\ln x) /(x-I)-\ln A\} d x \\
& \int \mathrm{I} \\
& +\int t_{1}|x-I|\{[\operatorname{lng}(x)] /(x-I)-(\ln x) /(x-I)-\ln A\} d x
\end{aligned}
$$

Since $0 \leq x \leq 1$, then $(64)$ reduces to,

$$
\begin{aligned}
\min : S & =-\int 0[\ln y(x)-B \ln x-(x-I) \ln A] d x+\int t I[\ln y(x)-B \ln x-(x-I) \ln A] d x \\
A, B & \\
& \int \mathrm{t}_{1} \\
& -\int \mathrm{t}_{2}[\ln y(x)-B \ln x-(x-I) \ln A] d x
\end{aligned}
$$

Differentiate "S" partially with respect to "A", "B", tı and tz and equate them to zero,

$$
\begin{aligned}
& \begin{array}{l}
\delta S \quad I \int \mathrm{t}_{1} \quad \int \mathrm{t}_{2} \quad \int \mathrm{I} \\
---=-\left[\int 0(\mathrm{x}-\mathrm{I}) \mathrm{d} \mathrm{d}-\int \mathrm{t}_{1}(\mathrm{x}-\mathrm{I}) \mathrm{d} \mathrm{x}+\int \mathrm{t}_{2}(\mathrm{x}-\mathrm{I}) \mathrm{dx}\right]=0
\end{array} \\
& \delta \mathrm{A} \quad \mathrm{A} \\
& \delta \mathrm{S} \quad \mathrm{t}_{1} \quad \mathrm{t}_{2} \quad \int \mathrm{I} \\
& ---=\int 0 \ln (\mathrm{x}) \mathrm{dx}-\int \mathrm{t}_{1} \ln (\mathrm{x}) \mathrm{dx}+\int \mathrm{t}_{2} \ln (\mathrm{x}) \mathrm{dx}=0 \\
& \delta \mathrm{B} \\
& \delta \mathrm{S} \\
& \overline{\delta \mathrm{t}_{\mathrm{I}}}----2\left\{\ln \left[\mathrm{y}\left(\mathrm{t}_{\mathrm{I}}\right)\right]-\mathrm{B} \ln \left(\mathrm{t}_{\mathrm{I}}\right)-\left(\mathrm{t}_{\mathrm{I}}-\mathrm{I}\right) \ln (\mathrm{A})\right\}=0 \\
& \delta \mathrm{S} \\
& ----=2\left\{\ln \left[\mathrm{y}\left(\mathrm{t}_{2}\right)\right]-\mathrm{B} \ln \left(\mathrm{t}_{2}\right)-\left(\mathrm{t}_{2}-\mathrm{I}\right) \ln (\mathrm{A})\right\}=0
\end{aligned}
$$

The above system of simultaneous equations can be solved for the unknowns $\mathrm{t}_{1}, \mathrm{t} 2$, " $\mathrm{A}$ " and "B". Equation (66) is reduced to, $\mathrm{tt}_{1}^{2}-\mathrm{t}_{2}^{2}-2(\mathrm{t} \mathrm{t}-\mathrm{t} 2)-\mathrm{I} / 2=0$

Equation (67) can be written as, $\mathrm{t}_{1}\left(\ln \mathrm{t}_{1}-\mathrm{I}\right)-\mathrm{t}_{2}\left(\ln \mathrm{t}_{2}-\mathrm{I}\right)-\mathrm{I} / 2=0$

Calculate $\mathrm{tI}$ from $(70)$ as,

$$
\mathrm{t}_{1}=\mathrm{I} \pm V_{\mathrm{q}}\left(\mathrm{t}_{2}{ }^{2}-2 \mathrm{t}_{2}+3 / 2\right)
$$

Since OstIsI, we accept,

$$
\mathrm{t}_{\mathrm{I}}=\mathrm{I}-\sqrt{\left(\mathrm{t}_{2}{ }^{2}-2 \mathrm{t}_{2}+3 / 2\right)}
$$

Substitute t $\mathrm{t}_{\mathrm{f}}$ from (73) into (7I), and rearrange the terms, gives;

$$
\frac{\left.\left[\mathrm{I}-\sqrt{\left(\mathrm{t}_{2}{ }^{2}-2 \mathrm{t} 2\right.}+3 / 2\right)\right]}{\ln -\sqrt{\left.\left(\mathrm{t}_{2} 2^{2}-2 \mathrm{t}_{2}+3 / 2\right)\right]}}+\mathrm{t}_{2}-3 / 2+\sqrt{ }\left(\mathrm{t}_{2}{ }^{2}-2 \mathrm{t}_{2}+3 / 2\right)=0
$$

The root of equation (74) may be computed by a suitable numerical algorithm. However, it has been computed and rounded for five digits decimal point as,

$$
\mathrm{t}_{2}=0.40442
$$

Value of $\mathrm{tI}$ is derived by substituting $\mathrm{t} 2$ into (73); 


$$
\mathrm{t}_{\mathrm{I}}=0.07549
$$

Values of "B" and "A" are computed from (68) and (69) using $\mathrm{t}_{2}$ and $\mathrm{t}_{1}$ given by (75) and (76). Thus,

$$
\begin{aligned}
& \quad\left(\mathrm{t}_{2}-\mathrm{I}\right) \ln y\left(\mathrm{t}_{1}\right)-\left(\mathrm{t}_{1}-\mathrm{I}\right) \ln y\left(\mathrm{t}_{2}\right) \\
& \left.\mathrm{B}=---\mathrm{t}_{2}-\mathrm{I}\right) \ln \left(\mathrm{t}_{\mathrm{I}}\right)-\left(\mathrm{t}_{\mathrm{I}} \mathrm{I}\right) \ln \left(\mathrm{t}_{2}\right) \\
& \text { or, } \mathrm{B}=-0.84857 \ln [\mathrm{y}(0.07549)]+\mathrm{I} .3 \mathrm{I} 722 \ln [\mathrm{y}(0.40442)] \\
& \text { and, } \\
& \mathrm{A}=[\mathrm{y}(0.07549)]^{1.28986}[\mathrm{y}(0.40442)]^{-3.68126}
\end{aligned}
$$

Now, let us describe how equation (6I) for the model (32) and equations (78) and (79) for the model (33) can be used to estimate the parameters of the Lorenz curve when the probability distribution function is known. In the model (32) we should solve (44) for $x(v)=I-\sqrt{2} / 2$. On the other hand, we should find value of " $v$ " such that,

$$
x(v)=\int 0 f(w) d w=I-\sqrt{ } 2 / 2
$$

By substituting this value of "v" into (45), value of $y(I-\sqrt{2} / 2)$ is computed. The value $y(I-\sqrt{2} / 2)$ is used to compute the parameter "A" given by (6I) for model (32).

The procedure for the model (33) is also similar, with the difference that two values of "v" should be computed. Once two different values of " $v$ " are computed as follow,

$$
\begin{aligned}
& x(v)=\int 0 f(w) d w=0.07549 \\
& x(v)=\int 0 f(w) d w=0.40442
\end{aligned}
$$

Values of "v" are substituted in (45) to find $y(0.07549)$ and $y(0.40442)$. These values of "y" are used to compute the parameters of the model (33) by substituting them into (78) and (79).

The only problem remains is computation of related definite integrals of $x(v)$ defined by (80), (8I) and (82) which can be done by appropriate numerical methods such as the enclosed sample computer program coded for MathCAD II for a complete

\begin{tabular}{|c|c|c|c|c|c|c|}
\hline \multirow[t]{2}{*}{ Year } & \multicolumn{3}{|c|}{ Urban Data } & \multicolumn{3}{|c|}{ Rural Data } \\
\hline & $\begin{array}{c}\text { Sample } \\
\text { size }\end{array}$ & $\begin{array}{c}\text { Income } \\
\text { Mean }\end{array}$ & Income variance & $\begin{array}{c}\text { Sample } \\
\text { size }\end{array}$ & $\begin{array}{c}\text { Income } \\
\text { Mean }\end{array}$ & Income variance \\
\hline 1362 & $\mathrm{I} 4747$ & 918423 & II06I99100048 & 12440 & 471942 & 192638591017 \\
\hline 1363 & 14728 & 1034169 & II74389430497 & 12420 & 524623 & 351371674839 \\
\hline 1364 & 13976 & I037084 & 1792475461430 & 13587 & 531098 & 301917047049 \\
\hline 1365 & 2745 & II26638 & I3003897I04I5 & 3015 & 568557 & 404222563256 \\
\hline 1366 & 2748 & I I 47497 & I4I097625355I & 3018 & 710145 & 491696298459 \\
\hline 1367 & 3987 & I360I2I & 2551576757245 & 4331 & 908530 & I7430563I7I2I \\
\hline 1368 & 5492 & I505970 & 4786980002705 & 6028 & I05237I & 1019597224716 \\
\hline 1369 & 9095 & $201047 \mathrm{I}$ & I2587903327408 & 9348 & $\mathrm{I} 25 \mathrm{I060}$ & 5529127350603 \\
\hline 1370 & 9168 & 2840790 & 66958717265779 & 9504 & I563II6 & 7505679968729 \\
\hline
\end{tabular}
example.

\section{Income distribution in Iran}

In order to compute the Lorenz curve for Iran, we try to apply the above procedure for both (32) and (33) propositions and using log-normal distribution function assumption. The source of data is "Statistical Center of Iran" who computed the mean and variance of income for urban and rural families for the period of I362-I370 (I983-199I) from "Family Budget Surveys" of different years. These data are given in Table I. The amounts of mean and variance of income were used to derive the log-normal density function parameters $\mu$ and $\sigma$. The explained procedure of estimation then applied to the series of data of table I, and corresponding results are reported in Table 2. A sample computer program is also enclosed at the end of these pages.

Table I. 
Source: Statistical Center of Iran.

Table 2.

\begin{tabular}{|c|c|c|c|c|c|c|c|}
\hline \multirow[t]{3}{*}{$\overline{\text { Year }}$} & \multicolumn{3}{|c|}{ Gupta Model } & \multicolumn{4}{|c|}{ Bidabad Model } \\
\hline & $\mathrm{A}$ & Gini & Kakwani & $\mathrm{A}$ & $\mathrm{B}$ & Gini & Kakwani \\
\hline & \multicolumn{7}{|c|}{ Urban estimation } \\
\hline 1362 & 7.259 & 0.430 & 0.163 & $5.3 \mathrm{I} 4$ & I.2II & 0.426 & 0.161 \\
\hline I363 & 6.279 & 0.409 & 0.148 & 4.620 & $\mathrm{I} .204$ & 0.405 & 0.146 \\
\hline $\mathrm{I} 364$ & 8.915 & 0.457 & 0.183 & 6.500 & 1.217 & 0.453 & 0.181 \\
\hline 1365 & 5.943 & $0.40 \mathrm{I}$ & 0.143 & 4.385 & 1.202 & 0.397 & $0 . \mathrm{I} 4 \mathrm{I}$ \\
\hline 1366 & 6.158 & 0.407 & 0.146 & 4.535 & 1.203 & 0.402 & 0.144 \\
\hline $\mathrm{I} 367$ & 7.574 & 0.436 & 0.167 & 5.539 & $\mathrm{I} .2 \mathrm{I} 2$ & 0.432 & 0.165 \\
\hline 1368 & I I.02I & 0.482 & 0.203 & 8.034 & 1.223 & 0.480 & 0.202 \\
\hline \multirow[t]{2}{*}{1369} & I5.84I & 0.522 & 0.236 & II.676 & 1.227 & $0.52 \mathrm{I}$ & 0.236 \\
\hline & \multicolumn{7}{|c|}{ Rural estimation } \\
\hline 1370 & $42.2 \mathrm{II}$ & 0.605 & 0.313 & 33.118 & $\mathrm{I} .26 \mathrm{I}$ & 0.607 & 0.316 \\
\hline 1362 & 5.220 & 0.382 & 0.129 & 3.878 & I.I95 & 0.377 & 0.127 \\
\hline I363 & 7.099 & 0.427 & 0.160 & $5.20 \mathrm{I}$ & 1.210 & 0.423 & 0.159 \\
\hline $\mathrm{I} 364$ & 6.152 & 0.406 & 0.146 & 4.531 & $\mathrm{I} .203$ & 0.402 & 0.144 \\
\hline 1365 & 6.978 & 0.424 & 0.159 & 5.115 & I.209 & 0.420 & 0.157 \\
\hline 1366 & 5.718 & 0.396 & 0.139 & 4.227 & 1.200 & $0.39 \mathrm{I}$ & 0.137 \\
\hline 1367 & I I.025 & 0.482 & 0.203 & 8.037 & 1.223 & 0.480 & 0.202 \\
\hline 1368 & 5.472 & 0.389 & 0.134 & 4.054 & I.I98 & 0.384 & 0.132 \\
\hline 1369 & 17.955 & 0.534 & 0.247 & 13.258 & 1.227 & 0.533 & 0.247 \\
\hline 1370 & 15.683 & $0.52 \mathrm{I}$ & 0.235 & II.5I8 & 1.227 & 0.519 & 0.234 \\
\hline
\end{tabular}

\section{References}

Bidabad, Bijan (1987a) Least absolute error estimation. The First International Conference on Statistical Data Analysis Based on the Li norm and Related Methods, Neuchatel, Switzerland. http://www.bidabad.com/doc/lae-I.pdf

Bidabad, Bijan (1987b) Least absolute error estimation, part II. Submitted to the First International Conference on Statistical Data Analysis Based on the Li norm and Related Methods, Neuchatel, Switzerland. http://www.bidabad.com/doc/lae-II.pdf

Bidabad, Bijan (I988a) A proposed algorithm for least absolute error estimation. Proc. of the Third Seminar of Mathematical Analysis. Shiraz Univ., 24-34, Shiraz, Iran.

Bidabad, Bijan (I988b) A proposed algorithm for least absolute error estimation, part II. Proc. of the Third Seminar of Mathematical Analysis, Shiraz Univ., 35-50, Shiraz, Iran.

Bidabad, Bijan (1989a) Discrete and continuous Li norm regressions, proposition of discrete approximation algorithms and continuous smoothing of concentration surface, Ph.D. thesis, Islamic Azad Univ., Tehran, Iran. http://www.bidabad.com/doc/LI-norm-thesis-en.pdf

Bidabad, Bijan (1989b) Discrete and continuous Li norm regressions, proposition of discrete approximation algorithms and continuous smoothing of concentration surface, Ph.D. thesis, Islamic Azad Univ., Tehran, Iran. Farsi translation. http://www.bidabad.com/doc/LI-norm-thesis-fa.pdf

Bidabad, Bijan (2005). Li norm based computational algorithms. http://www.bidabad.com/doc/1I-article6.pdf

Bidabad, Bijan (2005). Li norm solution of overdetermined system of linear equations. http://www.bidabad.com/doc/lI- 
article5.pdf

Bidabad, Bijan (2005). Lı norm based data analysis and related methods. http://www.bidabad.com/doc/1I-articli.pdf

Bidabad, Bijan (2005). New algorithms for the Li norm regression. http://www.bidabad.com/doc/1I-article2.pdf

Bidabad, Bijan (2005). Comparative study of the Li norm regression algorithms. http://www.bidabad.com/doc/1I-articl3.pdf

Bidabad, Bijan (2005). Continuous Li norm estimation of Lorenz curve. http://www.bidabad.com/doc/1I-articl4.pdf

Bidabad, Bijan (2005). Continuous $\mathrm{L}_{\mathrm{I}}$ norm estimation of Lorenz curve when probability density function is known.

Bidabad, Bijan (2005). USA Income distribution counter-business-cyclical trend (Estimating Lorenz curve using continuous $\mathrm{L}_{1}$ norm estimation). First meeting of the Society for the Study of Economic Inequality (ECINEQ), Palma de Mallorca, Spain, July 20-22, 2005.

http://www.uib.es/congres/ecopub/ecineq/general.html

http://www.uib.es/congres/ecopub/ecineq/papers/039Bidabab.pdf

http://www.bidabad.com/doc/estimating-lorenz-us.pdf

Bidabad, Bijan, Hamid Shahrestani. (2008) An implied inequality index using Lı norm estimation of Lorenz curve. Global Conference on Business and Finance Proceedings. Mercedes Jalbert, managing editor, ISSN 193I-0285 CD, ISSN I94I-9589 Online, Volume 3, Number 2, 2008, The Institute for Business and Finance Research, Ramada Plaza Herradura, San Jose, Costa Rica, May 28-3I, 2008, pp. I48-I63. Global Journal of Business Research, Vol. 4, No. I, 2010, pp.29-45.

http://www.bidabad.com/doc/LI-Implied-inequality-index-4.pdf

http://www.bidabad.com/doc/SSRN-idI63I86I.pdf

Bidabad, Bijan, Functional form for estimating the Lorenz curve, Australasian Econometric meeting, Australian National University, Australia, 1989. American Finance \& Banking Review, 4(I), I7-21, 2019.

https://www.cribfb.com/journal/index.php/amfbr/article/view/286

http://www.bidabad.com/doc/functional-form-lorenz.pdf

http://www.bidabad.com/doc/functional-form-lorenz.pptx

Bidabad, Bijan, USA Income distribution counter-business-cyclical trend (Estimating Lorenz curve using continuous LI norm estimation). First meeting of the Society for the Study of Economic Inequality (ECINEQ), Palma de Mallorca, Spain, July 20-22, 2005.

http://www.bidabad.com/doc/estimating-lorenz-us.pdf

Cramer J.S. (1973) Empirical econometrics. North-Holland, Amsterdam.

Gupta M.R. (1984) Functional forms for estimating the Lorenz curve. Econometrica, 52, I3I3-I3I4.

Hobby C.R., J.R. Rice (1965) A moment problem in LI approximation. Proc. Amer. Math. Soc., I6, 665-670.

Kakwani N.C. (1980) Income inequality and poverty. New York, Oxford University Press.

Kakwani N.C. (1980) Functional forms for estimating the Lorenz curve: a reply. Econometrica, 48, I063-64.

Kakwani N.C., N. Podder (1976) Efficient estimation of the Lorenz curve and associated inequality measures from grouped observations. Econometrica 44, I37-I48. 
Kendall M., A. Stuart (1977) The advanced theory of statistics. vol.I, Charles Griffin \& Co., London.

Kripke B.R., T.J. Rivlin (I965) Approximation in the metric of $\mathrm{L}_{\mathrm{I}}(\mathrm{X}, \mathrm{u})$. Trans. Amer. Math. Soc., II9, IOI-22.

Lazarski E. (1975a) Approximation of continuous functions in the space L I. Automatika, 487, 85-93.

Lazarski E. (1975b) The approximation of the continuous function by the polynomials of power functions in $\mathrm{L}_{\mathrm{I}}$ space. Automatika, 487, 95-106.

Lazarski E. (1975c) On the necessary conditions of the uniqueness of approximation by the polynomials of power functions in L space. Automatika, 487, I07-II7.

Lazarski E. (I977) Approximation of continuous functions by exponential polynomials in the L I space. Automatika, 598, 8287.

Ptak V. (1958) On approximation of continuous functions in the metric $\int_{a}^{b}|x(t)| d t$ Czechoslovak Math. J. 8(83), 267-273.

Rasche R.H., J. Gaffney, A.Y.C. Koo, N. Obst (1980) Functional forms for estimating the Lorenz curve. Econometrica, 48, I06I-I062.

Rice J.R. (I964a) On computation of $\mathrm{L}_{\mathrm{I}}$ approximations by exponentials, rationals, and other functions. Math. Comp., I8, 390-396.

Rice J.R. (I964b) On nonlinear LI approximation. Arch. Rational Mech. Anal., I7 6I-66.

Rice J.R. (1964c) The approximation of functions, vol. I, linear theory. Reading Mass:, Addison-Wesley.

Rice J.R. (I969) The approximation of functions, vol. II, linear theory. Reading Mass:, Addison-Wesley.

Rice J.R. (I985) Numerical methods, software, and analysis. McGraw- Hill, ch. I I.

Rice J.R., J.S. White (I964) Norms for smoothing and estimation. SIAM Rev., 6, 243-256.

Salem A.B.Z., T.D. Mount (1974) A convenient descriptive model of income distribution: the gamma density. Econometrica, 42, III5-II27.

Singh S.K., G.S. Maddala (I976) A function for the size distribution of income. Econometrica, 44, 963-970.

Slottje D.J. (1989) The structure of earnings and the measurement of income inequality in the U.S., North-Holland Publishing Company, Amsterdam.

Taguchi T. (1972a) On the two-dimensional concentration surface and extensions of concentration coefficient and Pareto distribution to the two dimensional case-I. Annals of the Inst. of Stat. Math., vol. 24, no.2, 355-38I.

Taguchi T. (I972b) On the two-dimensional concentration surface and extensions of concentration coefficient and Pareto distribution to the two dimensional case-II. Annals of the Inst. of Stat. Math., vol. 24, no.3, 599-6I9.

Taguchi T. (1972c) Concentration polyhedron, two dimensional concentration coefficient for discrete type distribution and some new correlation coefficients etc. The Inst. of Stat. Math., 77-II5.

Taguchi T. (1973) On the two-dimensional concentration surface and extensions of concentration coefficient and Pareto distribution to the two dimensional case-III. Annals of the Inst. of Stat. Math., vol. 25, no.I, 2I5-237.

Taguchi T. (1974) On Fechner's thesis and statistics with norm p. Ann. of the Inst. of Stat. Math., vol. 26, no.2, I75-I93.

Taguchi T. (1978) On a generalization of Gaussian distribution. Ann. of the Inst. of Stat. Math., vol. 30, no.2, A, 2 I I-242.

Taguchi T. (I98I) On a multiple Gini's coefficient and some concentrative regressions. Metron, vol. XXXIX - N.I-2, 5-98. 
Taguchi T. (1983) Concentration analysis of bivariate Paretoan distribution. Proc. of the Inst. of Stat. Math., vol. 3I, no.I, I32.

Taguchi T. (1987) On the structure of multivariate concentration. Submitted to the First International Conference on Statistical Data Analysis Based on the L I Norm and Related Methods, Neuchatel, Switzerland.

Taguchi T. (1988) On the structure of multivariate concentration - some relationships among the concentration surface and two variate mean difference and regressions. CSDA, 6, 307-334.

Usow K.H. (I967a) On L I approximation: computation for continuous functions and continuous dependence. SIAM J. of Numer. Anal., 4, 70-88.

Watson G.A. (I98I) An algorithm for linear L I approximation of continuous functions. IMA J. Num. Anal., I, I57-I67.

\section{Copyrights}

Copyright for this article is retained by the author(s), with first publication rights granted to the journal. This is an open-access article distributed under the terms and conditions of the Creative Commons Attribution license (http://creativecommons.org/licenses/by/4.0/). 